\title{
Does sexual cannibalism secure genetic benefits of polyandry in a size-dimorphic spider?
}

\author{
Katharina Weiss ${ }^{1} \cdot$ Jasmin Ruch $^{1} \cdot$ Stefanie S. Zimmer ${ }^{1} \cdot$ Jutta M. Schneider $^{1}$ (D) \\ Received: 7 May 2020 / Revised: 10 July 2020 / Accepted: 3 August 2020 / Published online: 18 August 2020 \\ (C) The Author(s) 2020
}

\begin{abstract}
Females mate multiply despite numerous costs. It is well established that polyandry can result in sexual conflict, favoring male adaptations that prevent sperm competition often to the disadvantage of the female. Such adaptations are extreme in spiders with one-shot genitalia of which parts break off and act as mating plugs, rendering them dysfunctional. In the spider Argiope bruennichi, mating plugs effectively prevent further males from inseminating and males that inseminate and plug both genital openings of a female secure exclusive paternity. However, females frequently prevent monopolization by attacking and cannibalizing males during their first copulation, leaving their second spermatheca free for another male. Here, we test whether the high frequency of sexual cannibalism evolved as a female adaptation to resist monopolization and secure indirect benefits of polyandry. To standardize conditions, we double-mated females either with the same or two different males and prevented male consumption. Using a split-brood design, we raised offspring to maturity under poor and rich food conditions and measured their survival, duration of juvenile phase, and adult body mass. Under low food, daughters of polyandrous mothers matured later but slightly heavier than daughters of monandrous females. Since the adaptive value of this combination is unclear, these findings lend no conclusive support to our hypothesis. We discuss the stereotypic nature of the female attack in the context of antagonistic co-evolution considering previous studies that found modest direct benefits of cannibalism as well as a potential for non-additive benefits.
\end{abstract}

\section{Significance statement}

Sexual conflict is extreme in spiders where sexual cannibalism impairs male mating rates. Males of the spider Argiope bruennichi possess one-shot genitalia which they break off to plug female genital openings. They gain exclusive paternity with a female if two copulations are achieved and both genital openings plugged. Females, however, stereotypically attack every male at the onset of copulation, limiting most males to single copulation but retaining the option to secure potential benefits of polyandry. Previous studies revealed weak direct and non-additive indirect benefits of multiple mating. In this study, we tested for the presence of additive genetic benefits but again found only inconclusive evidence for adaptive differences in offspring quality between monandrous and polyandrous females. All results combined, we here speculate that the stereotypic female attack might be a ghost of a past antagonistic co-evolution.

Keywords Argiope bruennichi $\cdot$ Araneae $\cdot$ Araneidae $\cdot$ Polyandry $\cdot$ Indirect benefits $\cdot$ Sexual cannibalism

Communicated by N. Wedell

Jutta M. Schneider

jutta.schneider@uni-hamburg.de

1 Institute of Zoology, University of Hamburg, Martin-Luther-King-Platz 3, D-20146 Hamburg, Germany

\section{Introduction}

Polyandry, the phenomenon whereby females mate with more than one male during one reproductive cycle (Thornhill and Alcock 1983), is common and taxonomically widespread (Taylor et al. 2014). Early models of sexual selection assumed monandry as the prevalent mating pattern of females because of primary sexual differences due to anisogamy. Based on Bateman's classical experiment on Drosophila flies (Bateman 1948), the reproductive success of males, producing 
numerous small gametes, was thought to be limited mainly by the number of matings they can attain, while females are largely limited by the number of costly, nutrient-rich gametes they can produce and not by the number of matings (Bateman's principle). Often single copulation is enough to ensure fertilization of all eggs of a female (Hayashi 1998; Schneider et al. 2005). Moreover, additional matings can entail costs regarding the loss of time and energy (Watson et al. 1998), male harassment (e.g., Sakurai and Kasuya 2008; den Hollander and Gwynne 2009), genital damage (Crudgington and SivaJothy 2000), higher predation and infection risk (Fedorka and Zuk 2005; Han and Jablonski 2010), and reduced lifespan (Arnqvist and Nilsson 2000; McNamara et al. 2008). Yet, females are seldom monogamous.

Today, there is accumulating evidence that females can benefit from polyandry in multiple ways. Direct fitness advantages such as increased fertility or longevity are well documented (e.g., Arnqvist and Nilsson 2000, Jennions and Petrie 2000, Gershman 2010; but see, e.g., Brown et al. 2004). Such benefits may result from the acquisition of additional nutrients through nuptial gifts or energy-rich spermatophores (Lamunyon 1997; Rooney and Lewis 2002; Engqvist 2007) or even the cannibalization of males, at least in species with moderate sexual size differences (e.g., Birkhead et al. 1988; Elgar and Nash 1988; Fernández-Montraveta et al. 2014). In species in which males provide no material benefits, however, females may still gain indirect ("genetic") benefits, i.e., increased genetic diversity of clutches or offspring quality (Jennions and Petrie 2000; Zeh and Zeh 2001). Yet, whether the gain of indirect benefits from polyandry is a general phenomenon is strongly debated and in arthropods, empirical studies have yielded evidence both for (e.g., Fedorka and Mousseau 2002; Ivy and Sakaluk 2005; Simmons 2005; Maklakov and Lubin 2006; Tuni et al. 2013; Kawazu et al. 2017) and against (e.g., Bilde et al. 2009; Maklakov and Arnqvist 2009; Okada et al. 2017) the evolutionary significance of additive genetic benefits.

From the male perspective, polyandry will favor adaptations to win sperm competition (e.g., larger ejaculates) or to avoid it, for example, by reducing a female's mating rate, which may lead to sexual conflict (Simmons 2001; Hosken et al. 2009). In several entelegyne spiders, for instance, males can effectively monopolize females by plugging their genital openings with parts of their sperm-transferring organs, albeit at the cost of very restricted mating rates (Uhl et al. 2010). Female entelegyne spiders have complex reproductive organs with two separate copulatory openings leading to two separate spermathecae (Foelix 2011). Males can generally only use one of their likewise paired secondary mating organs, the pedipalps, at a time to inseminate one of a female's two spermathecae. During copulation, males of some species break off fragments of the sperm-transferring part of the pedipalp, the embolus, which remain inside the copulatory duct as mating plugs and prevent further males from inseminating the same spermatheca (Nessler et al. 2007; Uhl et al. 2010). This break off renders the pedipalp dysfunctional and thus limits males to a maximum of two copulations (Uhl et al. 2010). Moreover, the mating system of many orb-web spiders is characterized by female-biased sexual size dimorphism and often high rates of post-copulatory sexual cannibalism, i.e., the consumption of a male by a female during or after mating (Schneider and Fromhage 2010; Schneider 2014).

In the wasp spider Argiope bruennichi, females invariably try to capture their mates during copulation, and about $80 \%$ of males are actually cannibalized during their first mating (Fromhage et al. 2003; Schneider et al. 2006). Of the surviving males, about $33 \%$ follow a monogamous strategy and monopolize the first female (Welke et al. 2012). A mathematical model by Fromhage et al. (2005) shows that a monogynous strategy can evolve under a male-biased effective sex ratio because fertilizing all eggs of a single female will return above-average reproductive success. In A. bruennichi, males plug the genital opening during mating and these plugs have been found to be almost 100\% effective (Nessler et al. 2007). However, since few males survive to mate on both sides, the second genital opening is often left available for another sire. This raises the question of whether the aggressive attacks of females that prevent most males from gaining exclusive paternity may have evolved to defend the females' own evolutionary interests if they benefit from mating multiply. However, the existence of such benefits is not entirely clear. Previous studies collected some evidence that polyandry could mitigate the negative effects of inbreeding (Zimmer et al. 2014; Zimmer and Schneider 2016). The only previous study that investigated direct genetic benefits in A. bruennichi, however, was unable to show benefits of polyandry for females (Welke and Schneider 2012). Yet, this study only tested offspring quality by comparing spiderling survival during winter, while nothing is known about possible fitness advantages after this stage.

Here we fill this gap by testing whether polyandry will increase offspring quality after emergence from the egg sac. Therefore, we raised offspring from monandrous and polyandrous A. bruennichi females that were mated twice with the same male or once each with two different males, respectively, under poor and high-food conditions in a split-brood design. We compared survival, the duration of the juvenile phase, and adult body mass of F1 spiderlings to test whether offspring from polyandrous mothers have fitness advantages over those from monandrous mothers.

\section{Material and methods}

\section{Study animals}

Argiope bruennichi (Scopoli, 1772) (Araneae, Araneidae) is an orb-web spider that is common in the Mediterranean area 
where it inhabits dry meadows with low, patchy vegetation, and has expanded its range to Northern Europe during the last century (e.g., Kumschick et al. 2011). We collected subadult males and females of $A$. bruennichi from a meadow in Pevestorf (Lower Saxony, Germany) shortly before the start of the mating season in early July 2011. Spiders were brought to our laboratory at the University of Hamburg, Germany, where they were individually housed in upturned plastic cups until their adult molt (males, $250 \mathrm{ml}$; females, $330 \mathrm{ml}$ ). Spiders were kept under natural light conditions at a constant temperature of $25^{\circ} \mathrm{C}$ and relative humidity of $45 \%$. Twice per week, males were fed with approximately 15 Drosophila $\mathrm{sp}$. and females with three Calliphora sp. houseflies. All spiders were provided with water from a sprayer 5 days per week. After their final molt, adult females were individually transferred into Perspex frames $(36 \times 36$ and 5 -cm depth) where they could build their typical orb webs.

\section{Experimental procedure}

\section{Mating treatment}

After their final molt, the field-caught females were assigned to one of two different mating treatments, monandrous or polyandrous, while controlling for mating rate. In the monandrous treatment, females were mated with the same male twice. To achieve second copulation with the same male, we prevented females from cannibalizing the male during the first copulation by gently placing a soft paintbrush on their chelicerae. In the polyandrous treatment, females were mated with two different males. To control for male mating status and to ensure that each male inseminated one of the two spermathecae, the 2 nd male had mated once before and was picked to have an unused pedipalp that matched the virgin insemination duct of the female. Note that due to the fixed copulation scheme, each pedipalp can only be inserted into the matching duct. By documenting the pedipalp used by the first male, we can be sure about the used genital opening. To exclude possible direct benefits of cannibalism (Welke and Schneider 2012), all females were prevented from cannibalizing the males. Egg sacs built by mated females were assigned individual IDs and placed outside into a mesh wire enclosure to overwinter under semi-natural conditions.

\section{Food treatment}

In March 2012, the egg sacs were transferred into a climate chamber where they could stepwise adapt to conditions similar to the laboratory for 1 week before they were finally brought back to the laboratory. In the laboratory, the egg sacs were opened carefully and the emerging F1 spiderlings were kept in groups inside plastic containers $(15 \times 11.5 \mathrm{~cm}$, height $7.5 \mathrm{~cm}$ ) where they built their communal hunting web. The plastic containers were sprayed with water five times a week and spiderlings were provided with approximately 20 Drosophila flies per container twice a week. As soon as spiderlings started to build their own capture webs, they were separated into individual plastic cups and assigned individual IDs according to the egg sac they originated from and the mating history of their mother.

In total, we obtained $499 \mathrm{~F} 1$ spiders from $19 \mathrm{~F} 0$ females $\left(N_{\text {monandrous }}=243, N_{\text {polyandrous }}=256\right)$. Of these, 153 individuals died during an early developmental phase, but all 19 families had between five and 23 members that survived. In a split-brood design, half of the surviving 346 spiderlings from monandrous and polyandrous mothers, respectively, were assigned to one of two different food treatments with either high or low-food availability. In the high-food availability treatment, females were fed with 2-3 Calliphora flies and males were fed with 15-20 Drosophila flies two times a week, so that they had uninterrupted food access (hereafter referred to as "high-food treatment"). In the low-food availability treatment, spiders were fed only once a week, and flies that had not been captured were removed on the fourth day after feeding (hereafter referred to as "low-food treatment"). The two different food treatments started with the separation of spiderlings into individual cups and were applied until they reached adulthood. All spiders were sprayed with water 6 days a week. Fifteen individuals died after their assignment to a food treatment; thus, $331 \mathrm{~F} 1$ spiders reached adulthood. Table 1 lists the numbers of F1 spiders that survived to adulthood in each of the four treatment groups based on their origin (monandrous or polyandrous mother) and the food treatment.

Spiders were monitored for molts daily. We noted the date of their adult molt, as well as the date of death if a spider did not survive until adulthood. On the day of the final molt, we determined adult body mass to the nearest $0.1 \mathrm{mg}$ by weighing the spiders on an electronic precision balance (Mettler Toledo, Modell AB54 -S).

\section{Statistical analysis}

To analyze whether the two life-history measures "duration of juvenile phase" (i.e., days between separation and adult

Table 1 Numbers of male and female F1 spiders in each of the four treatment groups that survived until their adult molt based on their origin (monandrous or polyandrous mother) and the food treatment

\begin{tabular}{lllll}
\hline Origin & Food treatment & $N$ Females & $N$ Males & $N$ total \\
\hline Monandrous & High & 59 & 27 & 86 \\
Monandrous & Low & 48 & 28 & 76 \\
Polyandrous & High & 55 & 36 & 91 \\
Polyandrous & Low & 51 & 27 & 78 \\
\hline
\end{tabular}


molt) and "adult body mass" were predicted by the origin and food treatment, we fitted generalized estimating equations (GEE) for males and females separately using the package "geepack" (Halekoh et al. 2006) in R (Version 2.15.3; R Development Core Team 2013). We used GEE models, which are suitable for clustered data, rather than generalized linear models because we wanted to include family ID as a random term to control for potential family effects (see Pekár and Brabec 2018). We used the Gaussian error structure and exchangeable structure and included "origin" and "food treatment" as factors, as well as their interaction. Maximal models were simplified by stepwise elimination of the least significant variables (starting with the interaction term) and models were compared with Wald statistics to test whether the explanatory power of reduced models was significantly lowered. Seven females could not be weighed on the day of their adult molt; thus, they are only included in the model for the duration of the juvenile phase $(N=213)$ but not in that for body weight $(N=206)$.

Furthermore, we analyzed the effect of monandrous and polyandrous origin on mortality by a chi-square test using the statistical program JMP (Version 7.0). In this analysis, we included all 499 F1 spiderlings. Since 153 of the 168 spiderlings that did not survive until adulthood died before we could determine their sex and allocate them to food treatment, we were only able to analyze the effect of monandrous and polyandrous origin on mortality but not the effect of the feeding treatment. All values given in the results section are means \pm standard deviation.

\section{Results}

\section{Duration of the juvenile phase}

In the high-food treatment, females generally grew faster (45.4 \pm 5.8 days, $N=114$ ) than in the low-food treatment (58.4 \pm 7.8 days, $N=99, \mathrm{t}=13.951, p<0.0001)$. The duration of the juvenile phase of females was predicted by an interaction of food treatment and origin (GEE: Wald statistics: $\chi^{2}=$ $\left.7.93, p=0.0049, N_{\text {clusters }}=19, N_{\text {individuals }}=213\right)$. The interaction describes that in the low-food treatment, female offspring from polyandrous mothers needed more time to reach adulthood ( $61.2 \pm 7.0$ days, $N=51)$ compared with those from monandrous mothers ( $55.4 \pm 7.4$ days, $N=48 ; t=-3.904, p=$ $0.0002)$, while there was no such difference in the high-food treatment $(t=-0.811, p=0.4191$; Fig. 1a). In males, origin had no effect on the duration of the juvenile phase, which was predicted by food treatment only (GEE: Wald statistics: $\chi^{2}=$ 53.3, $\left.p<0.0001, N_{\text {clusters }}=19, N_{\text {individuals }}=118\right)$. Males from the high-food treatment grew faster $(35.0 \pm 5.9$ days until adulthood, $N=63$ ) than males from the low-food treatment (43.4 \pm 8.6 days until adulthood, $N=55$; Fig. 1 b).
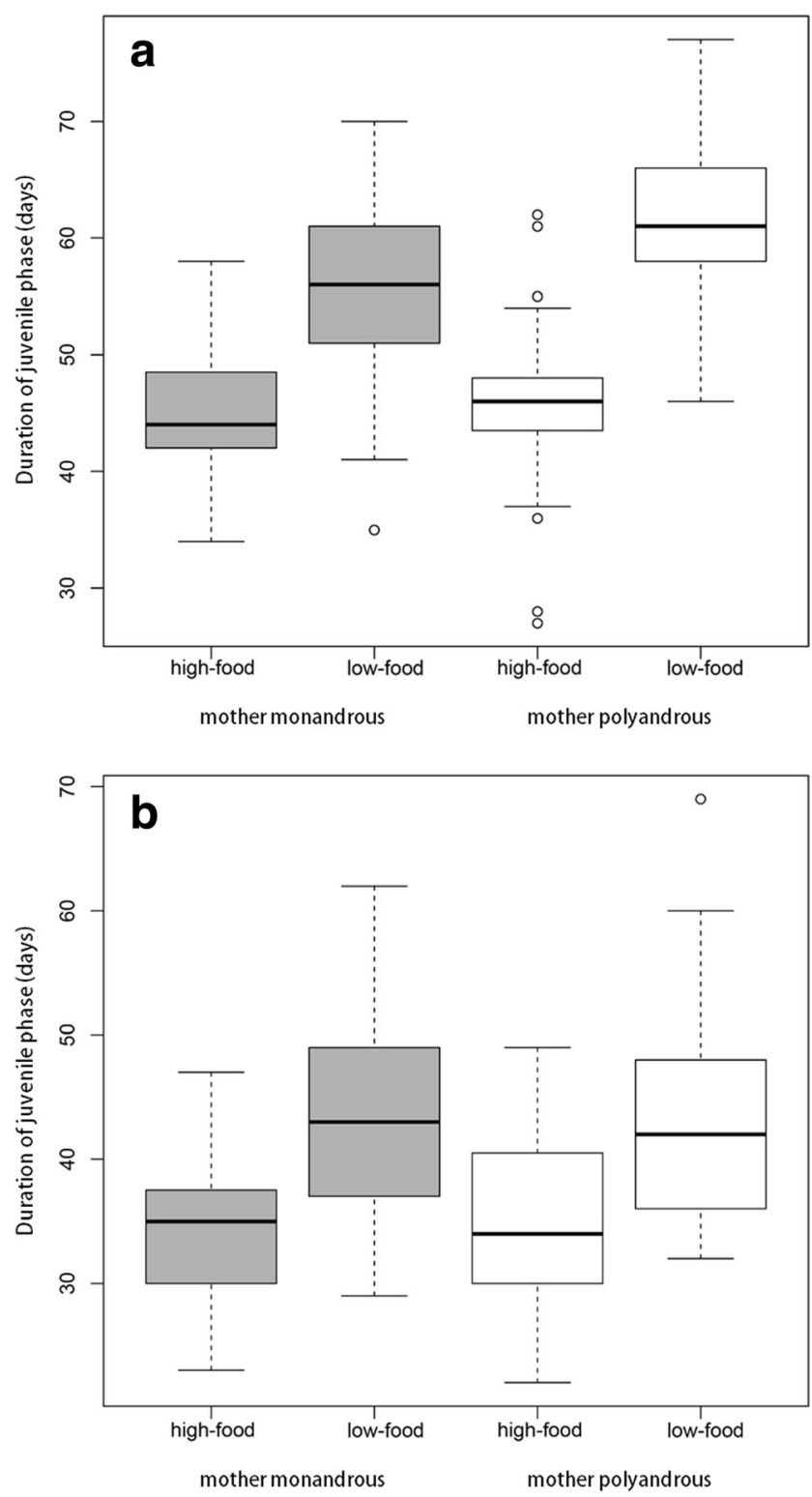

Fig. 1 Median duration of juvenile phase (as days between separation and adult molt) for a female and $\mathbf{b}$ male Argiope bruennichi in the four different treatment groups (numbers of individuals in each group are given in Table 1); horizontal line inside box, median; box, 25-75 percent quartiles; whiskers, extremes; open circles, outliers

\section{Adult body mass}

Female adult body mass was predicted by both origin and food treatment (but not their interaction; Fig. 2a). Females from the high-food treatment were significantly larger than females from the low-food treatment $(135.3 \pm 39.4 \mathrm{mg}$ and $69.3 \pm 29.9 \mathrm{mg}$, respectively; GEE: Wald statistics: $\chi^{2}=149, p<0.0001, N_{\text {clusters }}$ $\left.=19, N_{\text {individuals }}=206\right)$ and females from polyandrous mothers were heavier than those from monandrous mothers $(110.8 \pm$ $46.9 \mathrm{mg}$ and $99.0 \pm 49.0 \mathrm{mg}$, respectively; GEE: Wald statistics: $\left.\chi^{2}=3.87, p=0.049, N_{\text {clusters }}=19, N_{\text {individuals }}=206\right)$. The significance derives from the low-food treatment where 

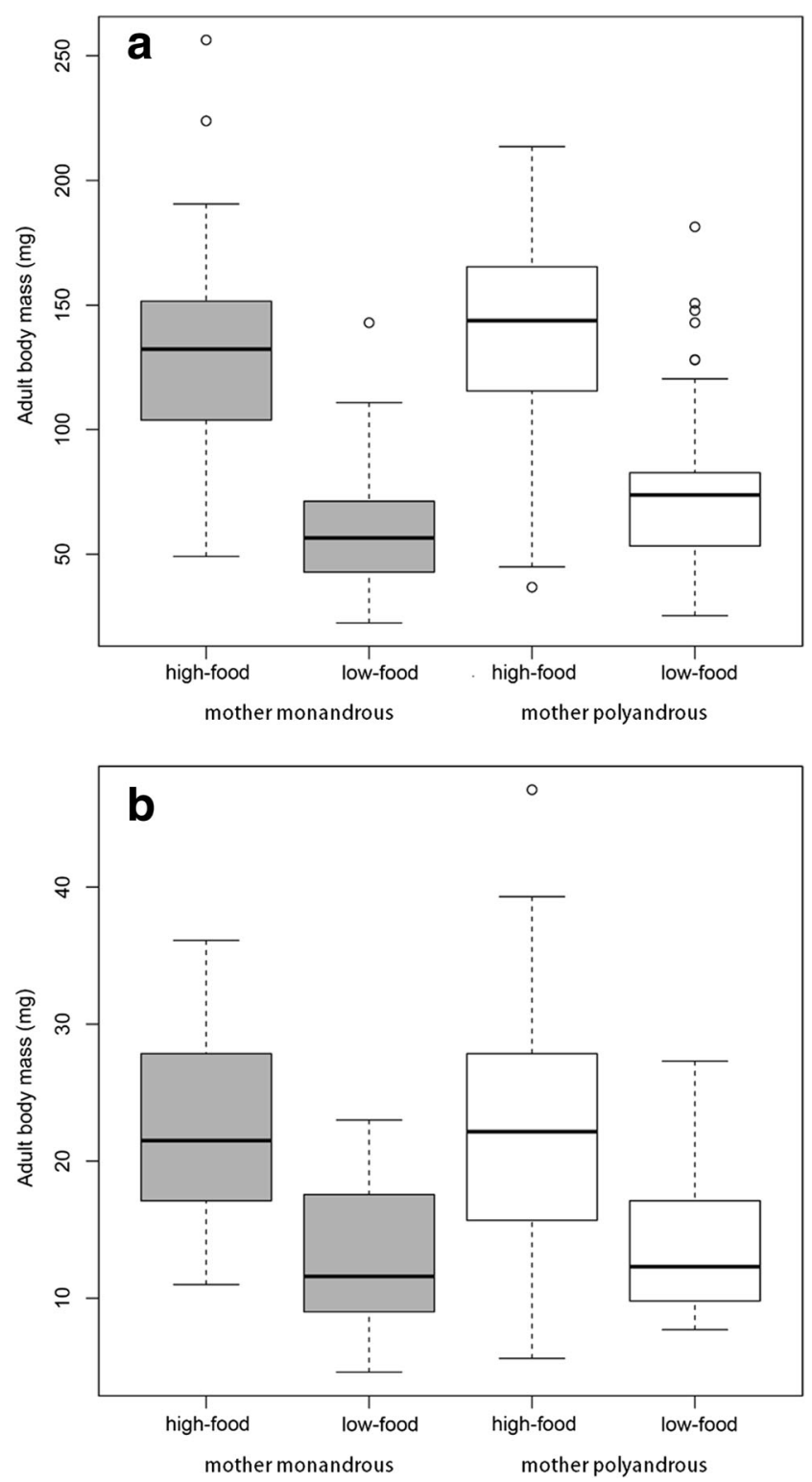

Fig. 2 Median adult body mass for a female and $\mathbf{b}$ male Argiope bruennichi in the four different treatment groups (numbers of individuals in each group are given in Table 1); horizontal line inside box, median; box, 25-75 percent quartiles; whiskers, extremes; open circles, outliers

daughters of polyandrous females $(77.7 \pm 32.2 \mathrm{mg}, N=49)$ matured significantly heavier than daughters of monandrous mothers $(60.2 \pm 24.1 \mathrm{mg}, N=46 ; t=-2.942, p=0.004)$. In the high-food treatment, daughters of polyandrous mothers were slightly but not significantly heavier $(140.8 \pm 36.9 \mathrm{mg}, N=54)$ than daughters of monandrous $(130.1 \pm 41.0 \mathrm{mg}, N=57 ; t=-$ $1.419, p=0.159)$. Male adult body mass, however, was only predicted by food treatment (GEE: Wald statistics: $\chi^{2}=53.0, p<$ $\left.0.0001, N_{\text {clusters }}=19, N_{\text {individuals }}=118\right)$ with males from the high-food treatment weighing $22.6 \pm 8.3 \mathrm{mg}(N=63)$ as compared with $13.0 \pm 4.8 \mathrm{mg}(N=55)$ in males from the low-food treatment (Fig. 2b).

\section{Mortality}

In total, 86 spiders from polyandrous mothers $(33.6 \%)$ died $14.9 \pm 11.6$ days after their separation into individual cups. From monandrous mothers, 82 spiders $(33.8 \%)$ died $17.1 \pm$ 11.7 days after their separation. Thus, mortality was not affected by origin (likelihood ratio: $N=168, \chi^{2}=0.007, p=$ $0.93)$.

\section{Discussion}

By raising offspring from polyandrous and monandrous mothers, we tested the hypothesis that Argiope bruennichi females aggressively attack and often cannibalize males during the first copulation because monopolization of paternity withholds genetic benefits of polyandry. Drastic measures by females to pursue their presumed interests are necessary for this species because males very effectively plug the genital opening of a female during mating and two copulations by the same male generally result in single paternity. Plugging is a costly male adaptation to prevent sperm competition as it entails irreversible damage to their paired genitalia, limiting males to a maximum of two copulations (Nessler et al. 2007). However, less than $30 \%$ of males achieve their maximal mating rate but get killed during their first copulation (Fromhage et al. 2003; Schneider et al. 2006). The maintenance of such high success rates of female sexual cannibalism despite high costs for males may imply high gains for females. We raised offspring from 19 families to maturity and tested whether females that mated once with two different males each (polyandrous) gained additive genetic benefits in comparison with females that mated twice with the same male (monandrous).

Our results, however, provide ambiguous support for this hypothesis. While there were no differences in mortality or in growth and adult size of sons, daughters from polyandrous mothers matured with larger body weight than daughters from monandrous mothers under the low feeding treatment. Since in spiders, as in other arthropods, body weight at maturation is a reliable predictor of female fecundity (Marshall and Gittleman 1994), this may constitute a reproductive advantage for polyandrous females. However, daughters of polyandrous mothers also required more time to mature as compared with those of monandrous mothers, again only under low-food conditions. This prolonged juvenile phase is likely directly linked with their larger adult body weight. However, it is much less straightforward to assign an adaptive value to later maturation than to a higher body mass. In general, maturing early is considered advantageous because it guarantees the best mating opportunities and a longer reproductive period (Roff 1992). Particularly, the latter may be of high relevance for A. bruennichi because their reproductive window in 
Northern Europe is very short (Zimmer et al. 2012). Moreover, a prolonged juvenile phase also increases the risk of dying before reaching the reproductive phase (Nylin and Gotthard 1998). Thus, especially when developmental conditions are not favorable, delaying maturation will unlikely constitute a general advantage. We therefore caution that reaching a slightly larger adult body mass by prolonging the juvenile phase cannot be interpreted as an advantage of polyandry. Moreover, since the variation in adult weight was large within all treatments and the differences related to mating rate were relatively small in females and absent in sons, we would not feel confident to conclude that our findings suggest that females gain genetic benefits from polyandry. In comparison, a study with the cellar spider, Pholcus phalangioides found that daughters of polyandrous mothers matured at a larger adult size than daughters of monandrous mothers but without a prolonged juvenile phase (Uhl et al. 2005). Thus, this effect can be interpreted as a fitness advantage of polyandry with some confidence. Unfortunately, except for a study by Maklakov and Lubin (2006) on Stegodyphus lineatus, we are not aware of another study that tested for benefits of polyandry and reported adult size or weight as well as the duration of the juvenile phase.

Polyandrous females may produce higher quality offspring due to additive genetic effects by increased chances that they are fathered by a male with a higher genetic quality or via nonadditive effects due to reduced risk that offspring are sired by an incompatible male (Jennions and Petrie 2000). Our experimental design cannot distinguish between these two mechanisms. Ivy (2007) suggests that phenotypic variance in developmental times and adult body mass are more likely influenced by non-additive effects, while additive effects may find expression in offspring survival to adulthood. We found no differences in mortality across treatments and one possible explanation might be that our food treatments were insufficient to reveal enhanced offspring survival under adverse conditions (Uhl et al. 2005). Although we applied a split-brood design to account for possible genotype-by-environment interactions (Hunt et al. 2004), we only varied the overall quantity of food but still provided prey on a regular basis even in the low-food treatment. Moreover, we did not vary prey quality. Under natural conditions, prey likely not only varies in quantity but also in quality and especially in its availability over time. Even though our food regimes produced significant differences in body weights and timing of maturation in both sexes, it might have been too good still to reveal stronger evidence for the indirect benefits of polyandry.

Spiders are generally assumed to be food limited (Wise 1995) and in many species, males supplement the diet of their mates, e.g., through nuptial gifts or nutritional ejaculates (Vahed 1998). Females will then gain more nutrients by mating multiply. Such direct benefits of polyandry are reported from several spider studies, e.g., in Pisaura mirabilis (Toft and Albo 2015) where males offer females prey items wrapped in silk (Prokop and Maxwell 2012). Indeed, polyandry has positive direct effects on female fecundity and egg hatching (Tuni et al. 2013). In other spiders, particularly in species with modest sexual size dimorphism, females will gain significant nutritional benefits from consuming males (Wilder et al. 2009). In the present study, we controlled for direct benefits that females may gain through the number of copulations and particularly through the consumption of males. A previous study on A. bruennichi in our lab used a similar mating design and experimentally varied whether females actually consumed the males they had killed or not. The dependent variable, however, was not the full development of offspring but offspring survival during hibernation (Welke and Schneider 2012). Interestingly, the consumption of males enhanced offspring survival during winter, but these benefits were independent of the number of males consumed and independent of the number of mates of the mother. A follow-up experiment compared the cannibalism of a male to food supplements with a selection of essential nutrients (Wilder and Schneider 2017). However, while supplementing food for the mother with essential amino acids positively affected the survival of spiderlings over winter, the effect of consuming males could not be replicated. An explanation for this inconsistency could be that in Welke and Schneider (2012), males were collected from the wild whereas in Wilder and Schneider (2017) males were raised in the laboratory, under a less diverse diet. This study should be replicated again using males and females from the field and the lab and assess whether essential amino acids might be in shortage in the field (Wiggins et al. 2018). If so, the male body, despite being very small might indeed be a valuable addition for the female diet and this effect might explain selection on females to maximize their chances to consume at least one male. Even though all males sacrifice their body after their second copulation, particularly small females risk to miss out when a male survives the first copulation and then leaves to find another mate (Welke et al. 2012, Cory and Schneider 2020).

Next to direct benefits, the best-supported benefits of polyandry in arthropods are indeed non-additive effects that arise for instance in the context of inbreeding (e.g., Tregenza and Wedell 2002; Bretman et al. 2004). Tregenza and Wedell (2000) argue that non-additive benefits are likely important in explaining the prevalence of polyandry in this taxon. Spiders are susceptible to inbreeding depression, but this may only become apparent after several generations of inbreeding (e.g., Bilde et al. 2007). Mating experiments in A. bruennichi, however, showed highly reduced egg hatching rates in $\mathrm{F} 1$ offspring from sibling crosses, suggesting that the costs of inbreeding in A. bruennichi are very high (Zimmer et al. 2014). In Argiope lobata, a Mediterranean congener of our study species, double-mating experiments using sibling and non-sibling males showed that females exert cryptic 
female choice and follow a trading up strategy in that they readily accepted siblings as mates but biased paternity in favor of unrelated males if they had the chance (Welke and Schneider 2009). While cryptic female choice has been demonstrated to occur in A. bruennichi favoring courting males (Schneider and Lesmono 2009), it remains to be tested for sibling matings. Yet, natural populations of A. bruennichi show high genetic diversity and no fine-scale genetic structure within populations indicating a rather modest risk of inbreeding under natural conditions (Zimmer et al. 2014; Zimmer and Schneider 2016). Thus, genetic diversity between F0 individuals in our study might have been too high to reveal inbreeding depression in monandrous females.

Besides inbreeding avoidance, another non-additive benefit of polyandry can be the mitigation of negative effects of selfish genetic elements (Wedell 2013) like bacterial endosymbionts that occur in a wide range of arthropods including spiders (e.g., Zhang et al. 2018) and can severely affect reproduction (Champion de Crespigny et al. 2008). For example, in the dwarf spider Oedothorax gibbosus, clutches of Wolbachia-infected females are significantly female biased (Vanthournout et al. 2011), and infection with Rickettsia bacteria lowers the tendency for long-distance dispersal behavior ("ballooning") in another dwarf spider, Erigone atra (Goodacre et al. 2009). In A. bruennichi, no known endosymbionts have been found so far (Duron et al. 2008; Yun et al. 2011; Sheffer et al. 2020). Yet, a recent microbiome analysis detected a novel dominant bacterium that is related to the Mollicutes (Sheffer et al. 2020), a bacterial class containing many arthropod-associated endosymbionts (e.g., Meeus et al. 2012; Sapountzis et al. 2018). Given that this bacterium might actually constitute a novel endosymbiont of $A$. bruennichi (Sheffer et al. 2020), it is tempting to speculate whether it might have any influence on the mating system of A. bruennichi including selection for polyandry.

Taken together, our data currently provide ambiguous support for the hypothesis that the killing of a male by the female during the first copulation evolved to retain opportunities for beneficial polyandry in A. bruennichi. Evidence from several experiments testing direct and additive as well as non-additive indirect benefits of polyandry suggests that perhaps a mix of several small advantages is what matters in A. bruennichi. However, the question of why females behave so aggressively towards all their mates, depriving the majority of these males of half their maximal mating success, remains open. Interestingly, the female attack behavior is highly stereotyped usually occurring within a split second of genital contact. Indeed, there appears to exist no obvious variation among females so that survival of the first copulation depends entirely on the male's ability to escape (Fromhage et al. 2003; Schneider et al. 2005; Welke and Schneider 2010). Assuming that the stereotypic behavior of the female is a product of sexually antagonistic co-evolution, the lack of variation suggests that this behavioral response is genetically fixed and has reached an extreme form on which selection can no longer act. Potential benefits of preventing low-quality or incompatible males from monopolizing paternity may have existed earlier in the evolutionary history of the species but are masked now that all females do the same. Similar experiments on related species with more flexible use of aggressive behavior during the first copulation may be revealing. Indeed, there is a large variation in the frequency of sexual cannibalism among species of the genus Argiope (Schneider et al. 2015), opening up the possibility of comparative studies on sexual antagonistic co-evolution in this spider genus. On the other hand, fitness costs for females of killing a male after a single mating might be comparatively small or even absent, given that females in natural population are normally visited by several males in the course of a mating season (Zimmer et al. 2012) and the fact that even one copulation suffices to fertilize several egg sacs (Schneider et al. 2005). Thus, considering selection for aggressiveness in different ecological contexts or under more severe experimental conditions, like prolonged periods of inbreeding or more natural food regimes, may ultimately explain the origin of female mating behavior and the high frequency of sexual cannibalism in A. bruennichi.

Acknowledgements We thank Simon Emken, Sarah Seidel, Tomma Dirks, and Angelika Taebel-Hellwig for raising and maintaining the spiders and for performing the experiments.

Availability of data and material Data will be uploaded to DRYAD. Reviewers can obtain data upon request.

Authors' contributions J.M.S. and S.M.Z. conceived the study and supervised data collection. S.M.Z., J.R., and K.W. analyzed the data. K.W., J.R., S.M.Z., and J.M.S. wrote the manuscript. All authors read and approved the final manuscript.

Funding information Open Access funding provided by Projekt DEAL. The study was funded by a DFG grant to J.M.S.

\section{Compliance with ethical standards}

Conflict of interest The authors declare that they have no conflict of interest.

Ethics approval Not applicable

Consent to participate Not applicable

Consent for publication Not applicable

Code availability (software application or custom code) Not applicable

Open Access This article is licensed under a Creative Commons Attribution 4.0 International License, which permits use, sharing, adaptation, distribution and reproduction in any medium or format, as long as you give appropriate credit to the original author(s) and the source, provide a link to the Creative Commons licence, and indicate if changes were made. The images or other third party material in this article are included in the article's Creative Commons licence, unless indicated otherwise in a 
credit line to the material. If material is not included in the article's Creative Commons licence and your intended use is not permitted by statutory regulation or exceeds the permitted use, you will need to obtain permission directly from the copyright holder. To view a copy of this licence, visit http://creativecommons.org/licenses/by/4.0/.

\section{References}

Arnqvist G, Nilsson T (2000) The evolution of polyandry: multiple mating and female fitness in insects. Anim Behav 60:145-164

Bateman AJ (1948) Intra-sexual selection in Drosophila. Heredity 2:349368

Bilde T, Maklakov AA, Schilling N (2007) Inbreeding avoidance in spiders: evidence for rescue effect in fecundity of female spiders with outbreeding opportunity. J Evol Biol 20:1237-1242

Bilde T, Foged A, Schilling N, Arnqvist G (2009) Postmating sexual selection favors males that sire offspring with low fitness. Science 324:1705-1706

Birkhead TR, Lee KE, Young P (1988) Sexual cannibalism in the praying mantis Hierodula membranacea. Behaviour 106:112-118

Bretman A, Wedell N, Tregenza T (2004) Molecular evidence of postcopulatory inbreeding avoidance in the field cricket Gryllus bimaculatus. Proc R Soc Lond B Biol Sci 271:159-164

Brown WD, Bjork A, Schneider K, Pitnick S (2004) No evidence that polyandry benefits females in Drosophila melanogaster. Evolution 58:1242-1250

Champion de Crespigny FE, Hurst LD, Wedell N (2008) Do Wolbachiaassociated incompatibilities promote polyandry? Evolution 62:107122

Cory AL, Schneider JM (2020) Males of a sexually cannibalistic spider chemically assess relative female quality. BMC Evol Biol 20:90. https://doi.org/10.1186/s12862-020-01657-w

Crudgington HS, Siva-Jothy MT (2000) Genital damage, kicking and early death. Nature 407:855-856

den Hollander M, Gwynne DT (2009) Female fitness consequences of male harassment and copulation in seed beetles, Callosobruchus maculatus. Anim Behav 78:1061-1070

Duron O, Hurst GD, Hornett EA, Josling JA, Engelstädter JAN (2008) High incidence of the maternally inherited bacterium Cardinium in spiders. Mol Ecol 17:1427-1437

Elgar MA, Nash DR (1988) Sexual cannibalism in the garden spider Araneus diadematus. Anim Behav 36:1511-1517

Engqvist L (2007) Nuptial food gifts influence female egg production in the scorpionfly Panorpa cognata. Ecol Entomol 32:327-332

Fedorka KM, Mousseau TA (2002) Material and genetic benefits of female multiple mating and polyandry. Anim Behav 64:361-367

Fedorka KM, Zuk M (2005) Sexual conflict and female immune suppression in the cricket, Allonemobious socius. J Evol Biol 18:1515-1522

Fernández-Montraveta C, González JM, Cuadrado M (2014) Male vulnerability explains the occurrence of sexual cannibalism in a moderately sexually dimorphic wolf spider. Behav Process 105:53-59

Foelix R (2011) Biology of spiders. Oxford University Press, New York

Fromhage L, Uhl G, Schneider JM (2003) Fitness consequences of sexual cannibalism in female Argiope bruennichi. Behav Ecol Sociobiol 55:60-64

Fromhage L, Elgar MA, Schneider JM (2005) Faithful without care: the evolution of monogyny. Evolution 59:1400-1405

Gershman SN (2010) Large numbers of matings give female field crickets a direct benefit but not a genetic benefit. J Insect Behav 23:59-68
Goodacre SL, Martin OY, Bonte D, Hutchings L, Woolley C, Ibrahim K, Thomas DFG, Hewitt GM (2009) Microbial modification of host long-distance dispersal capacity. BMC Biol 7:32

Halekoh U, Højsgaard S, Yan J (2006) The R package geepack for generalized estimating equations. J Stat Softw 15:1-11

Han CS, Jablonski PG (2010) Male water striders attract predators to intimidate females into copulation. Nat Commun 1:52

Hayashi F (1998) Multiple mating and lifetime reproductive output in female dobsonflies that receive nuptial gifts. Ecol Res 13:283-289

Hosken DJ, Stockley P, Tregenza T, Wedell N (2009) Monogamy and the battle of the sexes. Annu Rev Entomol 54:361-378

Hunt J, Bussiere LF, Jennions MD, Brooks R (2004) What is genetic quality? Trends Ecol Evol 19:329-333

Ivy TM (2007) Good genes, genetic compatibility and the evolution of polyandry: use of the diallel cross to address competing hypotheses. J Evol Biol 20:479-487

Ivy TM, Sakaluk SK (2005) Polyandry promotes enhanced offspring survival in decorated crickets. Evolution 59:152-159

Jennions MD, Petrie M (2000) Why do females mate multiply? A review of the genetic benefits. Biol Rev Camb Philos 75:21-64

Kawazu K, Sugeno W, Mochizuki A, Nakamura S (2017) Polyandry increases reproductive performance but does not decrease survival in female Brontispa longissima. Bull Entomol Res 107:165-173

Kumschick S, Fronzek S, Entling MH, Nentwig W (2011) Rapid spread of the wasp spider Argiope bruennichi across Europe: a consequence of climate change? Clim Chang 109:319-329

Lamunyon C (1997) Increased fecundity, as a function of multiple mating, in an arctiid moth, Utetheisa ornatrix. Ecol Entomol 22:69-73

Maklakov AA, Arnqvist G (2009) Testing for direct and indirect effects of mate choice by manipulating female choosiness. Curr Biol 19: 1903-1906

Maklakov AA, Lubin Y (2006) Indirect genetic benefits of polyandry in a spider with direct costs of mating. Behav Ecol Sociobiol 61:31-38

Marshall SD, Gittleman JL (1994) Clutch size in spiders: is more better? Funct Ecol 8:118-124

McNamara KB, Elgar MA, Jones TM (2008) A longevity cost of remating but no benefits of polyandry in the almond moth, Cadra cautella. Behav Ecol Sociobiol 62:1433-1440

Meeus I, Vercruysse V, Smagghe G (2012) Molecular detection of Spiroplasma apis and Spiroplasma melliferum in bees. J Invertebr Pathol 109:172-174

Nessler SH, Uhl G, Schneider JM (2007) Genital damage in the orb-web spider Argiope bruennichi (Araneae: Araneidae) increases paternity success. Behav Ecol 18:174-181

Nylin S, Gotthard K (1998) Plasticity in life-history traits. Annu Rev Entomol 43:63-83

Okada K, Suzaki Y, Sasaki R, Katsuki M (2017) Fitness costs of polyandry to female cigarette beetle Lasioderma serricorne. Behav Ecol Sociobiol 71:86

Pekár S, Brabec M (2018) Generalized estimating equations: a pragmatic and flexible approach to the marginal GLM modelling of correlated data in the behavioural sciences. Ethology 124:86-93

Prokop P, Maxwell MR (2012) Gift carrying in the spider Pisaura mirabilis: nuptial gift contents in nature and effects on male running speed and fighting success. Anim Behav 83:1395-1399

R Development Core Team (2013) R: a language and environment for statistical computing. R Foundation for Statistical Computing, Vienna, Austria. http://www. R-project. org. R Foundation for Statistical Computing, Vienna, Austria

Roff DA (1992) The evolution of life histories: theory and analysis. Chapman and Hall, New York

Rooney J, Lewis SM (2002) Fitness advantage from nuptial gifts in female fireflies. Ecol Entomol 27:373-377

Sakurai G, Kasuya E (2008) The costs of harassment in the adzuki bean beetle. Anim Behav 75:1367-1373 
Sapountzis P, Zhukova M, Shik JZ, Schiott M, Boomsma JJ (2018) Reconstructing the functions of endosymbiotic Mollicutes in fungus-growing ants. ELife 7:e39209

Schneider JM (2014) Sexual cannibalism as a manifestation of sexual conflict. CSH Perspect Biol 6:a017731

Schneider J, Fromhage L (2010) Monogynous mating strategies in spiders. In: Kappeler P (ed) Animal behaviour: evolution and mechanisms. Springer, Berlin, pp 441-464

Schneider JM, Lesmono K (2009) Courtship raises male fertilization success through post-mating sexual selection in a spider. Proc Biol Sci 276:3105-3111

Schneider JM, Fromhage L, Uhl G (2005) Extremely short copulations do not affect hatching success in Argiope bruennichi (Araneae, Araneidae). J Arachnol 33:663-669

Schneider JM, Gilberg S, Fromhage L, Uhl G (2006) Sexual conflict over copulation duration in a cannibalistic spider. Anim Behav 71:781788

Schneider J, Uhl G, Herberstein ME (2015) Cryptic female choice within the genus Argiope: a comparative approach. In: Peretti A, Aisenberg A (eds) Cryptic female choice in arthropods. Springer, Cham, pp $55-77$

Sheffer MM, Uhl G, Prost S, Lueders T, Urich T, Bengtsson MM (2020) Tissue-and population-level microbiome analysis of the wasp spider Argiope bruennichi identified a novel dominant bacterial symbiont. Microorganisms 8:8

Simmons LW (2001) Sperm competition and its evolutionary consequences in the insects, vol 68. Princeton University Press, Princeton

Simmons LW (2005) The evolution of polyandry: sperm competition, sperm selection, and offspring viability. Annu Rev Ecol Evol Syst 36:125-146

Taylor ML, Price TA, Wedell N (2014) Polyandry in nature: a global analysis. Trends Ecol Evol 29:376-383

Thornhill R, Alcock J (1983) The Evolution of Insect Mating Systems. Harvard University Press, Cambridge

Toft S, Albo MJ (2015) Optimal numbers of matings: the conditional balance between benefits and costs of mating for females of a nuptial gift-giving spider. J Evol Biol 28:457-467

Tregenza T, Wedell N (2000) Genetic compatibility, mate choice and patterns of parentage: invited review. Mol Ecol 9:1013-1027

Tregenza T, Wedell N (2002) Polyandrous females avoid costs of inbreeding. Nature 415:71-73

Tuni C, Albo MJ, Bilde T (2013) Polyandrous females acquire indirect benefits in a nuptial feeding species. J Evol Biol 26:1307-1316

Uhl G, Schmitt S, Schäfer MA (2005) Fitness benefits of multiple mating versus female mate choice in the cellar spider (Pholcus phalangioides). Behav Ecol Sociobiol 59:69-76

Uhl G, Nessler SH, Schneider JM (2010) Securing paternity in spiders? A review on occurrence and effects of mating plugs and male genital mutilation. Genetica 138:75-104

Vahed K (1998) The function of nuptial feeding in insects: a review of empirical studies. Biol Rev 73:43-78
Vanthournout B, Swaegers J, Hendrickx F (2011) Spiders do not escape reproductive manipulations by Wolbachia. BMC Evol Biol 11:15

Watson PJ, Stallmann RR, Arnqvist G (1998) Sexual conflict and the energetic costs of mating and mate choice in water striders. Am Nat 151:46-58

Wedell N (2013) The dynamic relationship between polyandry and selfish genetic elements. Philos Trans R Soc Lond Ser B Biol Sci 368: 20120049

Welke K, Schneider JM (2009) Inbreeding avoidance through cryptic female choice in the cannibalistic orb-web spider Argiope lobata. Behav Ecol 20:1056-1062

Welke KW, Schneider JM (2010) Males of the orb-web spider Argiope bruennichi sacrifice themselves to unrelated females. Biol Lett 6: 585-588

Welke KW, Schneider JM (2012) Sexual cannibalism benefits offspring survival. Anim Behav 83:201-207

Welke KW, Zimmer SM, Schneider JM (2012) Conditional monogyny: female quality predicts male faithfulness. Front Zool 9:7

Wiggins WD, Bounds S, Wilder SM (2018) Laboratory-reared and fieldcollected predators respond differently to same experimental treatments. Behav Ecol Sociobiol 72:19

Wilder SM, Schneider JM (2017) Micronutrient consumption by female Argiope bruennichi affects offspring survival. J Insect Physiol 100: $128-132$

Wilder SM, Rypstra AL, Elgar MA (2009) The importance of ecological and phylogenetic conditions for the occurrence and frequency of sexual cannibalism. Annu Rev Ecol Evol Syst 40:21-39

Wise DH (1995) Spiders in ecological webs. Cambridge University Press, Cambridge

Yun Y, Peng Y, Liu FX, Lei C (2011) Wolbachia screening in spiders and assessment of horizontal transmission between predator and prey. Neotrop Entomol 40:164-169

Zeh JA, Zeh DW (2001) Reproductive mode and the genetic benefits of polyandry. Anim Behav 61:1051-1063

Zhang L, Yun Y, Hu G, Peng Y (2018) Insights into the bacterial symbiont diversity in spiders. Ecol Evol 8:4899-4906

Zimmer SM, Schneider JM (2016) Fine-scale spatial genetic structure suggests modest risk of inbreeding in natural populations of Argiope bruennichi. Evol Ecol Res 17:35-51

Zimmer SM, Welke KW, Schneider JM (2012) Determinants of natural mating success in the cannibalistic orb-web spider Argiope bruennichi. PLoS One 7:e31389

Zimmer SM, Schneider JM, Herberstein ME (2014) Can males detect the strength of sperm competition and presence of genital plugs during mate choice? Behav Ecol 25:716-722

Publisher's note Springer Nature remains neutral with regard to jurisdictional claims in published maps and institutional affiliations. 